\title{
NOVAS FORMAS INSTITUCIONAIS DE PARTICIPAÇÃO NA DEMOCRACIA BRASILEIRA - PERSPECTIVAS E LIMITES
}

\author{
Rodrigo Stumpf González
}

\begin{abstract}
Resumo
Nos últimos anos o Brasil vem realizando eleições periódicas para os poderes executivo e legislativo, com candidaturas vinculadas aos partidos políticos, sem que estes consigam conquistar a confiança da população. As críticas aos limites de funcionamento das instituições representativas levaram à proposição de instrumentos e espaços alternativos para a participação popular. Novas formas de intervenção nas decisões do poder público têm surgido ao longo das últimas duas décadas. Este artigo busca analisar os limites e possibilidades de algumas destas novas formas de participação política.
\end{abstract}

Palavras-chave: Democracia; Participação; Conselho Tutelar; Iniciativa Popular Legislativa.

\begin{abstract}
In the last years Brazil has done periodical elections to executive and legislative political branches, with candidates affiliated to political parties, with none of them achieving popular confidence. Criticism to the limits of representative institutions has taken to the proposal of new instruments and alternative spaces of popular participation. New forms of intervention in public power decisions have been emerged in the last two decades. The aim of this article is analyzing the limits and possibilities of some of these new ways of political participation.
\end{abstract}

Keywords: Democracy; Participation; Guardian Council; People's Legislative Initiative.

\section{Introdução}

O conceito de democracia é alvo, nos últimos séculos, de intensas disputas em relação a seu significado. Conforme dito por Alan Wolfe (1980), a democracia não é um conceito estático, ela necessita de adjetivos.

Muito tem sido dito e escrito sobre a democracia representativa, suas limitações e a busca de alternativas, entre as quais estaria a democracia participativa (GONZÁLEZ, 2000).

As principais instituições, organizações e processos associados à democracia representativa são o Poder Executivo, o Poder Legislativo, os partidos políticos e as eleições para ocupar os cargos institucionais.

Já em relação à democracia participativa, as instituições e processos não são tão definidos, podendo ser utilizados, em cada realidade, diferentes formas para sua realização (GONZÁLEZ, 2000). 
Porém mesmo usando um conceito minimalista de democracia os períodos de experiência democrática na história brasileira são relativamente curtos, em relação à sua história. Dos 512 anos desde o início da colonização européia, 322 foram de domínio colonial português, 67 de Império, marcado pelo uso do voto censitário e Poder Moderador do Imperador. Mesmo considerando os anos de história republicana iniciada em 1889, há poucos momentos que podemos considerar como razoavelmente democráticos.

$\mathrm{Na}$ República Velha o Brasil possuía uma sociedade ainda predominantemente rural, na qual se mantinham arranjos políticos que Victor Nunes Leal (1986) denominou de "coronelismo", como o controle sobre a participação com o "voto de cabresto".

A modernização do regime político brasileiro e a aceleração de seu processo de industrialização e urbanização foram iniciadas de forma autoritária com a Revolução de 30, na prática, um golpe de uma aliança civilmilitar liderada por Getúlio Vargas.

A tentativa de redemocratização com o regime constitucional iniciado em 1934 teve curta duração, sendo rapidamente substituído pelo Estado Novo, mantida a liderança de Getúlio.

A República Liberal (1946-1964), mesmo mantendo um período contínuo de 18 anos, com eleições livres não foi despida completamente de percalços, podendo se destacar a proibição de funcionamento do $P C B$, então um dos partidos com maior representação no congresso nacional, em 1948, sob a influência da Guerra Fria; o suicídio de Getúlio Vargas em 1954, sob a pressão de um possível golpe de estado; o movimento da Legalidade, pela defesa da posse de João Goulart, seguida da emenda parlamentarista, do plebiscito definindo pelo retorno ao presidencialismo e, finalmente, o golpe militar de abril de 1964 (CARONE, 1985).

Neste período, nos espaços urbanos se desenvolveram um sindicalismo e um movimento comunitário que se sustentam em arranjos clientelistas, com tutela do estado, assim como alguns movimentos de protesto rural, como as ligas camponesas, destruídos ou desorganizados pela repressão do regime militar, principalmente depois de 1968.

A chegada a um novo período democrático, marcada pela transmissão da Presidência da República a um civil em 1985, foi antecedida de um longo processo de transição negociada, iniciado com a "Distensão" no Governo Geisel (1974-1979) e seguido da "Abertura" no Governo Figueiredo (19791985).

No entanto, desde o final dos anos 70 a sociedade brasileira vivia o despertar de novas formas de organização social, destacando-se o surgimento de um novo movimento sindical e de movimentos sociais em diferentes áreas (SADER, 1988).

Estes movimentos tiveram uma participação importante durante a Assembléia Nacional Constituinte nos anos 1987/88, particularmente na 
mobilização de emendas populares ao projeto de constituição (WHITAKER, 1989).

A partir dos anos 80 foi delineado um novo sistema partidário, cujos partidos principais e seus sucessores continuam dominando a representação eleitoral. Ao PT, PTB, PDT, PMDB somam-se a linha sucessória do hoje PP (PDS-PPR-PPB-PP), o PFL e o PSDB. Alguns partidos com bancadas menores completam o quadro, como PL, PSB, PCB (PPS). Além destes, com a facilidade da legislação da época, foi criada uma constelação de pequenos partidos, sem expressão nacional (GONZÁLEZ, 2001).

Mesmo com esta grande quantidade de partidos, as críticas à sua capacidade de representação continuam sendo um dos problemas da política brasileira (BAQUERO, 2000).

Em alguns casos os eleitos utilizaram os partidos como mero suporte a candidaturas pessoais. As siglas mais famosas nesta situação são provavelmente o PRN, que deu base à candidatura de Fernando Collor de Melo, para depois praticamente desaparecer, e o PRONA, que foi sustentado na figura carismática do Dr. Enéas Carneiro, caindo no ostracismo com sua morte.

Apesar da manutenção de eleições periódicas para os poderes executivo e legislativo, com candidaturas vinculadas aos partidos políticos, nem estes nem o poder legislativo conseguiram conquistar a confiança da população, sendo que a confiança e a satisfação nos ocupantes do poder executivo têm sido extremamente variável, embora este não seja um privilégio do Brasil (GONZÁLEZ, 2011).

As críticas aos limites de funcionamento das instituições representativas levaram à proposição de instrumentos e espaços alternativos para a participação popular. Novas formas de intervenção nas decisões do poder público têm surgido ao longo das últimas duas décadas. Algumas foram fruto da mobilização no processo constituinte e em seus desdobramentos, como a iniciativa popular. Outras iniciaram como experiências locais e extrapolaram este âmbito pelo sucesso ou pela divulgação, como o orçamento participativo. Este texto busca analisar os limites e possibilidades de alguns destes novos espaços de participação.

\section{Novos espaços de participação}

Se considerarmos a política como um processo de definição de preferências coletivas, a definição do uso do poder do Estado em uma democracia se concentra particularmente em quatro campos: a aprovação das leis, a definição das políticas públicas, a distribuição do orçamento público e o controle dos poderes de administração.

Tendo em vista a dificuldade de legitimação das instituições tradicionais da democracia representativa no exercício destas funções foram 
sendo propostos, nos últimos anos novos mecanismos de legitimação para a definição destes três campos de ação estatal.

A primeira é a intervenção da população na definição de investimentos no orçamento público. O Estado do Rio Grande do Sul é pródigo em exemplos, como o caso do orçamento participativo na cidade de Porto Alegre. Desenvolvido desde 1991, o orçamento participativo estadual, promovido pelo Governo Olívio Dutra, do PT (1998-2002), em concorrência com o Fórum Democrático, da Assembléia Legislativa e a proposição do Governo Germano Rigotto, do PMDB, do Processo de Participação Popular (PPP) (GONZÁLEZ, 2007).

Outra experiência importante é a dos conselhos de controle de políticas públicas. A partir de um modelo pensado pela saúde, diversas outras áreas, como a assistência social, criança e adolescente, entre outras, adotaram a proposição de conselhos compostos por representação de entidades da sociedade civil e do governo, nas três esferas de governo - municipal, estadual e nacional.

Uma terceira tentativa de criação de espaços de participação popular foi a previsão na Constituição Federal da Iniciativa Popular Legislativa. Passados quase 18 anos a previsão constitucional tem sido substituída por um novo modelo, que são as comissões de legislação participativa no âmbito do congresso nacional e de assembléias legislativas estaduais.

Um quarto tipo de intervenção da população ao qual tem sido dada pouca atenção é a eleição de agentes públicos na esfera administrativa, como é o caso dos diretores de escolas e dos conselheiros tutelares.

Mais recentemente tem crescido a importância de um instrumento de intervenção indireta na formulação das políticas públicas que busca aumentar a transparência das decisões: A realização de audiências públicas.

Vejamos o funcionamento de cada uma destas estruturas e seus limites na expansão da democracia no Brasil.

\section{A definição do orçamento}

Segundo a legislação brasileira, o gasto público deve ser previamente autorizado, através de um conjunto de leis, que incluem o Plano Plurianual, as leis de diretrizes orçamentárias e as leis orçamentárias, estas últimas anuais. A iniciativa da lei que dispõe sobre os gastos do Poder Executivo é dos ocupantes deste poder - Prefeito, Governador ou Presidente da República, com aprovação pelo Poder Legislativo.

Nos últimos anos diversos municípios criaram sistemas de consulta à população para a elaboração do projeto de lei orçamentária. Embora não seja necessariamente o primeiro, o Orçamento Participativo, realizado na cidade de Porto Alegre foi certamente o de maior divulgação e sucesso.

Os mecanismos de funcionamento do Orçamento Participativo foram parcialmente modificados ao longo dos anos e são descritos em extensa 
bibliografia, da qual podemos destacar Fedozzi (1997), González (1998), González (2001) e Santos (2002).

O sucesso não apenas administrativo, mas como fator de sustentação política (O OP certamente contribuiu para as sucessivas reeleições do Partido dos trabalhadores em Porto Alegre) levou o PT, quando da vitória da Frente Popular nas eleições para o Governo do Estado do Rio Grande do Sul, em 1998, encabeçada por este partido, com a candidatura vitoriosa de Olívio Dutra, a propor a criação de um Orçamento Participativo Estadual (GONZÁLEZ, 2007).

$O$ OP Estadual foi organizado por antigos integrantes da equipe responsável pelo OP em Porto Alegre e propunha uma estrutura semelhante, com a realização de assembléias regionais para a escolha de prioridades e delegados, que compunham um conselho responsável pela preparação da proposta orçamentária e acompanhamento da execução.

A Assembléia Legislativa, apoiada em uma lei aprovada ${ }^{1}$ no final do Governo Antônio Britto, do PMDB (1995-1998), que dava competência aos Conselhos Regionais de Desenvolvimento para propor prioridades regionais ao orçamento, cria o "Fórum Democrático de Desenvolvimento Regional". O fórum é claramente uma tentativa de enfrentar o orçamento participativo estadual, o que fica claro no tom dos discursos em sua instalação, que seguem o clima de enfrentamento entre situação e oposição que caracterizou o período (RIO GRANDE DO SUL, 1999).

Com a eleição de Germano Rigotto, do PMDB, para o Governo do Rio Grande do Sul, em 2002, o orçamento participativo estadual foi extinto, sendo substituído pelo Processo de Participação Popular - PPP. Este processo utiliza alguns elementos do Fórum Democrático, sendo organizado com base em uma alteração da lei $11.179 / 98$. Neste processo os COREDES apontam uma lista de prioridades que são colocadas em votação pela população.

O diferencial maior entre os mecanismos do OP e do PPP está no fato do primeiro se basear na realização de assembléias populares, valorizando a participação direta como espaço de debate, fundando-se teoricamente nos valores da democracia grega, enquanto o segundo utiliza procedimentos plebiscitários, conforme experiências desenvolvidas no pós-guerra em diversos países, chamado por alguns autores de "democracia semi-direta".

Além destes mecanismos, no Rio Grande do Sul ainda é possível a apresentação de emendas populares ao projeto de lei orçamentária.

Cada um destes processos buscou consultar a população sobre prioridades de investimento público, de formas diferenciadas. Também tem em comum que o percentual de recursos do orçamento que é efetivamente objeto de discussão pela população é extremamente limitado.

As experiências de participação na definição do orçamento não se restringiram a Porto Alegre ou ao Rio Grande do Sul, existindo dezenas de

\footnotetext{
${ }^{1}$ Lei Estadual 11.179/98.
} 
cidades que adotaram modelos como maior ou menor semelhança aos descritos. Porém, quando da chegada de Lula à Presidência havia uma expectativa de que fosse implantado algum instrumento de consulta popular sobre o orçamento na esfera federal, o que acabou não acontecendo, apesar dos sucessivos mandatos do PT na presidência.

\section{Os Conselhos de Controle de Políticas Públicas}

A existência de conselhos, por si, não é uma novidade na política brasileira. Se não considerarmos o parlamentarismo do período imperial, com a existência de um Conselho de Ministros, o uso de conselhos como espaço de debate foi desenvolvido a partir dos governos de Getúlio Vargas, particularmente a partir do Estado Novo (GONZÁLEZ, 2000).

Vargas, dentro de uma concepção corporativa, criou diversos conselhos, com a finalidade de serem espaços de negociação das políticas do Estado. Estes conselhos, em certo sentido, preencheram naquele momento a ausência do Congresso Nacional como organismos para representação de interesses dos diversos segmentos da sociedade, e em especial do empresariado (DINIZ, 1981).

A criação de conselhos como organismos de apoio técnico ao processo decisório do Estado foi novamente valorizada durante o regime militar, período no qual foram criadas mais de duas dezenas de Conselhos em diversas áreas (GONZÁLEZ, 2000). Mas estes espaços guardam pouca relação com o modelo de conselhos que foi constituído no final da década de 80 , com o suporte do novo texto constitucional.

Paralelamente ao processo de abertura política, uma outra perspectiva de organização e mobilização social foi construída. Com a crise econômica e o aumento da desigualdade social, principalmente no meio urbano, novas formas de ação coletiva surgiram. Se, em muitos casos, foram fruto da organização espontânea da população, em alguns surgiram também sob a influência das CEBs - Comunidades Eclesiais de Base, da Igreja Católica (SINGER, 1980).

Estas formas foram discutidas largamente sob o título de "novos movimentos sociais" (BOSCHI, 1983 e 1987; SCHERER-WARREN e KRISCHKE, 1987). As práticas associativas em geral eram pouco institucionalizadas, sendo o enfrentamento contra o Estado, pela reivindicação de melhoria das condições de vida um dos elementos centrais da mobilização.

Conforme Jacobi (1983 e 1989) os moradores das periferias urbanas passam a reivindicar do Estado a prestação de serviços básicos, como postos de saúde e creches, organizando-se em associações de moradores, que irão gerar a formação de "conselhos populares".

Desta mobilização, potencializada pela redemocratização surgiram algumas das experiências de controle popular dos serviços locais de saúde, 
com a criação de conselhos, em 1979, em bairros de periferia de São Paulo, para controlar o funcionamento dos centros de saúde (JACOBI, 1983).

O movimento popular somou-se a segmentos organizados dos trabalhadores da saúde, no movimento da "Reforma Sanitária", dotando as reivindicações de grande poder de pressão. A realização de Conferências Nacionais de Saúde são momentos de maior mobilização. O primeiro passo é a criação do SUDS - Sistema Único Descentralizado de Saúde, ainda no Governo José Sarney (GONZÁLEZ, 2000).

Como resultado da mobilização durante a Assembléia Nacional Constituinte, reivindicações do Movimento da Reforma Sanitária foram incorporadas à Constituição de 1988 e também são adotados como princípio em outras áreas, como uma perspectiva de democratização: a descentralização da execução, com a perspectiva de municipalização do atendimento, e o controle social, com a criação de conselhos nas três esferas de governo, com a responsabilidade por deliberação e controle das políticas sociais em suas respectivas áreas de atuação. Além dos dispositivos referentes à saúde, a assistência social e a área da infância e juventude adoram a mesma perspectiva.

Por entraves na negociação das leis orgânicas, no entanto, a área da infância foi a primeira a ser regulamentada, através do Estatuto da Criança e do Adolescente, Lei 8069/90, de 13 de julho. Em seguida foi aprovada a Lei Orgânica da Saúde, 8080/90, em 19 de setembro, tendo, no entanto, vetados os dispositivos referentes aos Conselhos, que foram regulados pela lei 8142/90, de 29 de dezembro. A Lei Orgânica da Assistência Social foi vetada integralmente pelo então presidente Fernando Collor de Melo, sendo aprovada apenas em sete de dezembro de 1993, como lei 8742/93, já no Governo Itamar Franco.

Em comum estas leis propõem a criação de Conselhos municipais, estaduais e federais, com competências para deliberação de políticas em suas respectivas esferas. Nas áreas da saúde e assistência social os novos conselhos herdaram antigas estruturas, do Conselho Nacional de Saúde, criado em 1937 e do Conselho Nacional de Serviço Social, criado em 1938, ambos pelo Governo Vargas, que até então tinham funções consultivas.

No decorrer dos anos 90 foram propostos outros conselhos, seguindo o mesmo modelo, em áreas como a do Meio Ambiente e do Idoso, entre outras. Há uma verdadeira inflação de conselhos, com ou sem previsão de leis orgânicas federais. A inexistência de um conselho é vista, em muitos casos, como diminuição da importância e capacidade de reivindicação do segmento social.

A criação dos Conselhos nas diferentes áreas se deu na medida do poder de pressão, principalmente econômica, da esfera federal. Até 1994, um dos fatores de estímulo à criação de conselhos municipais e estaduais dos direitos da criança e do adolescente era a possibilidade de receber recursos da 
Fundação CBIA ${ }^{2}$, do Governo Federal que exigia como requisito de repasses a existência dos conselhos. Com a extinção desta em 1994, a criação de novos conselhos foi bastante mais lenta.

Ao mesmo tempo, com a formulação das Normas Básicas da Saúde e da Assistência Social, e o requisito de criação de conselhos nestas áreas para o repasse de recursos, hoje, ao menos formalmente, $100 \%$ dos municípios brasileiros conta com conselhos de saúde e a maioria possui conselhos de assistência social.

Não são, no entanto, incomuns os questionamentos sobre esta legitimidade. Conforme relata Raichelis (1998), citando o caso do Conselho Nacional de Assistência Social, em determinadas situações entram em choque a defesa da legitimidade do Poder Executivo para assumir a responsabilidade pela tomada de decisões, baseado em sua escolha pelo voto direto da população, com as competências dos Conselhos, que tem um perfil de representação fundado em organizações da sociedade.

Quando as duas perspectivas de representação entram em choque, a capacidade dos conselhos tomarem decisões que serão realmente implementadas varia conforme sua capacidade de mobilização social. E, neste caso, pela estrutura de representação corporativa que possuem a maioria dos conselhos, as fontes de pressão são, na maioria das vezes, restritas à esfera municipal, ainda que ocorram exceções (GONZÁLEZ, 2000).

Como parte do modelo de ação dos conselhos passaram a ser realizadas periodicamente conferências em suas respectivas áreas de interesse. Em geral em um processo piramidal, em que a temática é definida pelo nível mais alto, o federal, e o debate se dá nos espaços municipal e estadual até chegar a uma conferência nacional. No entanto, embora tenham se constituído em espaços válidos de avaliação das políticas públicas, as decisões das conferências têm pouco peso na definição final das políticas de governo, ficando muitas vezes restritas a espaços de questionamento. (MORONI, 2005 e 2006).

\section{A iniciativa popular}

A iniciativa popular pode ser caracterizada como uma quebra do monopólio dos poderes do Estado (Legislativo, Executivo e Judiciário) sobre a apresentação de projetos de lei.

A inclusão na Constituição Federal desta possibilidade, bem como no texto de inúmeras constituições estaduais e leis orgânicas municipais tem origem na grande mobilização ocorrida durante a Assembléia Nacional Constituinte, quando foi permitida a apresentação de emendas populares, mediante a coleta de assinaturas (WHITAKER et. al., 1989).

\footnotetext{
${ }^{2}$ Centro Brasileiro para a Infância e Adolescência.
} 
A iniciativa popular prevista na Constituição Federal, no entanto, praticamente se tornou letra morta, tanto pela dificuldade da coleta de assinaturas quanto pela falta de garantia de sua tramitação dentro do Congresso Nacional.

Com os dados das eleições gerais de 1998, a Tabela 1 apresenta uma simulação entre seis Estados que apresentam uma considerável representatividade de eleitores, como pode ser observada na coluna da porcentagem nacional. Comparando o número de eleitores com a porcentagem mínima exigida pela legislação constitucional (um por cento do eleitorado nacional, distribuído pelo menos por cinco Estados, com não menos de três décimos por cento dos eleitores de cada um deles - art.61, $\$ 2{ }^{\circ}$, Constituição Federal) (GONZÁLEZ e DINIZ, 2002).

Tabela 1 - Simulação para a ocorrência da Iniciativa Popular em seis estados da Federação de acordo com os dados das Eleições Gerais de 1998

\begin{tabular}{lccc}
\hline \multicolumn{1}{c}{ Estados } & $\mathbf{N} \mathbf{0}^{\mathbf{0}}$ eleitores & \% Nacional & $\mathbf{0 , 3 0 \%}$ \\
\hline Santa Catarina & 3.516 .819 & 3,31 & 10.550 \\
Rio Grande do Sul & 6.845 .988 & 6,45 & 20.538 \\
São Paulo & 23.309 .908 & 21,98 & 69.929 \\
Rio de Janeiro & 9.971 .925 & 9,40 & 29.915 \\
Minas Gerais & 11.815 .219 & 11,14 & 35.445 \\
Bahia & 7.932 .243 & 7,48 & 23.796 \\
\hline Total & 106.028 .696 & 59,76 & 106.028 \\
\hline
\end{tabular}

Fonte: Tribunal Superior Eleitoral e Instituto Brasileiro de Geografia e Estatística (1998).

O que é demonstrado nesta tabela é a expressiva quantidade de subscrições exigidas pela norma constitucional, o que pode ser considerado como um dos elementos que vem dificultando a sua utilização na prática. 0 outro fator que também pode ser considerado é o alto custo do procedimento. Uma campanha de subscrição de um projeto de lei em cinco Estados tem um alto custo financeiro que só poderá ser financiado pela sociedade organizada em instituições que estejam vinculadas e interessadas na proposta legislativa que estarão promovendo.

Como alternativa à inefetividade da iniciativa popular mediante a coleta de assinaturas, Câmara dos Deputados e Senado Federal criaram Comissões de Legislação Participativa. Como outras comissões internas são compostas por membros das respectivas casas e tem por função receber proposta de projetos de lei de pessoas e instituições, dando seguimento quando entenderem cabíveis.

$\mathrm{Na}$ Assembléia Legislativa do Rio Grande do Sul foi criada uma Comissão Mista Permanente de Participação Legislativa Popular, que recebe propostas de instituições tais como sindicatos, ONGs e órgãos de classe.

Estas iniciativas tentam diminuir uma sensação de distanciamento entre a população e os parlamentares, mas com efeitos ainda pouco visíveis. 
Poucos projetos de lei aprovados na esfera federal tiveram origem em iniciativa popular. A grande exceção é a chamada "Lei da Ficha Limpa", lei complementar 135/2010, que regula requisitos para as candidaturas às eleições, vetando candidatos com condenações prévias. Porém o projeto aprovado sofreu muitas alterações no Congresso Nacional em relação à proposta com a qual foram coletadas as assinaturas para a iniciativa popular.

\section{Eleição de agentes públicos}

Uma quarta modalidade que vem se desenvolvendo de intervenção na população na administração pública é a escolha, por via eletiva, de agentes públicos.

Podem ser destacados dois casos mais conhecidos desta modalidade: a escolha de dirigentes de estabelecimentos de ensino, como diretores de escolas ou reitores de universidade, por eleições realizadas com a participação de membros da comunidade escolar ou acadêmica como, alunos, funcionários e professores; e a eleição de conselheiros tutelares, função prevista no Estatuto da Criança e do Adolescente.

A escolha de diretores de escolas por via eletiva tem sido adotada em alguns Estados da Federação, como é o caso do Rio Grande do Sul. Normalmente se baseia em legislação estadual, variando os procedimentos. Nas universidades públicas também são vários os procedimentos, sendo prevista por lei nas universidades federais a consulta à comunidade para a definição de lista tríplice, sendo que a ordem de votação não é vinculativa da escolha por parte do Governo Federal.

Em ambos os casos, permite-se uma intervenção da comunidade na definição de um dirigente com poderes de gestão de orçamento público às vezes de montante não desprezível (há vários Estados em que o orçamento das Unidades Federais perde em valor apenas para o do Governo Estadual e do Governo Municipal da Capital, sendo maior que o dos demais municípios).

No caso dos Conselhos Tutelares, a legislação que prevê a sua criação já indica a natureza eletiva da função. Segundo o Estatuto da Criança e do Adolescente, os conselheiros tutelares devem ser escolhidos pela comunidade com mandato de três anos, permitida uma recondução (Art. 132 da Lei 8069/90). A previsão inicial de intervenção da justiça eleitoral foi considerada inconstitucional, sendo dada nova redação ao artigo ${ }^{3}$.

Como se trata de órgão municipal, cada município dispõe como se dá a participação da comunidade. Em alguns casos há a formação de um colégio eleitoral, composto por organizações sociais. Em outros é o Conselho Municipal dos Direitos da Criança e do Adolescente os escolhe. A tendência, no entanto, é de adotar uma eleição universal facultativa entre os eleitores do município.

\footnotetext{
${ }^{3}$ Lei $8242 / 1991$.
} 
Esta é uma inovação importante na legislação brasileira que tem passado despercebida. Há países, como os EUA, onde é comum a realização de eleições para funções administrativas, como Chefe de Polícia ou Promotor. No caso brasileiro há a previsão na Constituição Federal de eleição dos juízes de paz, dispositivo nunca colocado em prática.

O Conselho tutelar, no Brasil é provavelmente a primeira função pública de natureza territorial de caráter não político, com poderes administrativos, a ser eletiva. A legislação dá ao conselheiro tutelar poderes importantes para determinar medidas a pessoas e instituições. Sua limitação, no entanto, é que a legislação é frequentemente descumprida até mesmo pelos próprios municípios, limitando na prática os poderes concedidos aos Conselheiros Tutelares.

Por outro lado, a importância dos Conselheiros Tutelares nas comunidades tem sido reconhecida por uma outra capacidade, que é a de dar apoio ou originar candidaturas aos espaços políticos tradicionais. Por este motivo, em muitas cidades onde há eleições para o Conselho Tutelar os diretórios locais dos partidos políticos articulam-se para apresentar candidaturas nos bairros ou regiões de seu interesse. Outros espaços de articulação política, como as igrejas também têm seguido caminho semelhante.

\section{As audiências públicas}

Embora não exista um modelo único da audiência pública, este mecanismo de participação foi popularizado nos últimos anos pelos dispositivos da legislação ambiental, ao exigir reuniões públicas para discussão com os interessados projetos de infra-estrutura, como hidrelétricas com potencial de grande impacto social e ambiental.

A audiência pública coloca frente a frente os representantes dos diversos interesses envolvidos, o que pode redundar seja em acordos, seja em espaço de denúncias que alimentam a ação de órgãos como o Ministério Público. No entanto, sua natureza presencial cria limitações, como o tempo de manifestação a ser atribuído a cada um dos participantes, limitação já levantada por Dahl (1998).

Uma variação do procedimento das audiências públicas, que tem sido utilizada por agências reguladoras, conselhos de controle de políticas públicas, entre outros organismos com responsabilidade de editar normas reguladoras, são os processos de consulta pública, em que uma versão preliminar da norma é apresentada à população para sugestões e críticas. Neste caso o organismo consultor não delega seu poder de decisão, mas permite à população apontar possíveis desconformidades antes da edição da norma. 


\section{Efeitos políticos das novas formas de participação}

As modalidades de participação descritas acima, por vários motivos, têm limitações na mudança do perfil institucional da democracia brasileira, uma vez que os principais tomadores de decisões políticas continuam sendo os chefes do poder executivo e os membros do legislativo, com uma ampliação também crescente da intervenção do Poder Judiciário.

Porém sua existência e a experiência continuada destes instrumentos têm produzido efeitos indiretos na prática democrática em nosso país. A seguir são analisados alguns destes possíveis efeitos:

Um dos efeitos da criação de novos espaços institucionais é o aumento da informação disponível sobre a atuação da administração pública.

A discussão de prioridades orçamentárias ou da atuação de órgãos públicos pelos conselhos ou assembléias de orçamento participativo implica na oferta de dados, sua publicação ou mesmo transcrição em linguagem mais acessível. Os materiais publicados são feitos em maior tiragem, distribuídos ao público ou disponibilizados aos membros dos organismos de participação, que transferem esta informação a outras pessoas. Isto ajuda a romper uma das limitações da democracia apontadas por Bobbio (1986) como o poder oculto.

A participação em assembléias populares do orçamento participativo, dos debates de conferências, audiências públicas, fóruns e conselhos de políticas setoriais ou ainda da candidatura ou exercício da função em conselhos tutelares podem provocar dois efeitos positivos sobre a democracia: a) desenvolvimento de competência pessoal para intervenção política e b) surgimento de novas lideranças.

Em relação ao item "a", pessoas oriundas de segmentos da população normalmente alijados do processo político e com limitações de ingresso no mundo político por sua condição socioeconômica ou baixa escolaridade podem romper esta barreira por meio da participação iniciada em espaços compartilhados por pessoas de condição semelhante, vencendo esta barreira e adquirindo capacidades para a intervenção em outros espaços.

Estas podem ser desde vencer o "temor reverencial" de falar diante de autoridades como conhecer mecanismos para coordenar reuniões, inscreverse na lista de oradores, entre outros.

Este efeito pode contribuir para o outro: pessoas sentindo-se capazes de intervir em processos sociais passam a ingressar em novos espaços. Um dos fenômenos que tem ocorrido em cidades como Porto Alegre é o de lideranças surgidas em espaços como o orçamento participativo ou os conselhos tutelares se candidatarem, em alguns casos sendo eleitos, para a Câmara de Vereadores, ou passarem a ocupar funções na hierarquia da administração municipal, através de cargos comissionados.

A existência de mecanismos de participação nos quais o cidadão comum pode intervir, verificando após a existência de resultados, pode 
aumentar o seu sentimento de eficácia política, mesmo que esta eficácia, em alguns momentos, não seja real. Mas saber que "a minha opinião conta" ajuda a melhorar a auto-estima de parcelas da população normalmente excluídas do processo político, estimulando-as a interferir. Cabe notar que em processos como o orçamento participativo, este efeito tem sido mais visível em lideranças que na população em geral (SANTOS, 2002).

A realização de atividades coletivas dentro da comunidade, em prol de objetivos comuns pode fortalecer os laços de confiança, gerando a capacidade de propor ações em que o nível de compromisso seja mais profundo ou mesmo gerando a criação de espaços associativos permanentes, o que pode contribuir, a longo prazo, na formação de capital social.

Os efeitos descritos, no entanto, não são lineares, dotados de uma causalidade perfeita e sempre em sentido positivo, pois se tratam de processos complexos que interagem, não só no fortalecimento da democracia, mas, em alguns casos podem resultar no oposto.

Como dito anteriormente, em parte as modalidades de participação descritas estão relacionadas à descrença nos partidos políticos, parlamentos e poderes executivos como instâncias de representação de interesses. Esta descrença pode enfraquecer o apoio a estas instituições, além do que as novas práticas não são imunes às críticas dirigidas às instituições tradicionais.

Por exemplo, em alguns casos, os conselhos, podem vir a se constituir em formas de neocorporativismo, como representantes de segmentos da sociedade (GONZÁLEZ, 2000).

As diversas formas de participação não são neutras entre si ou em relação às instituições representativas tradicionais. $O$ orçamento participativo pode entrar em choque direto com a Câmara de Vereadores, que tem a competência legal para aprovação da lei orçamentária. Por outro lado, a definição de prioridades para investimento do OP pode entrar em choque com as definições de linhas para a política municipal em determinada área, segundo as definições de um conselho setorial, como os da saúde ou educação.

Qual a arena de decisão correta para dirimir estas disputas? Qual o espaço dotado de maior legitimidade para dar a última palavra? Estas provavelmente são questões cuja resposta não é consensual.

Podemos pensar em um modelo de sociedade ideal, na qual os dirigentes sejam eleitos, com responsabilidade perante o eleitor, orçamento público seja definido pela população, as políticas sejam controladas por conselhos compostos por cidadãos conscientes e preocupados com o bem comum, as mudanças nas leis propostas pela população. Alguns identificam este modelo com a democracia grega, outros como uma utopia.

Muito foi dito sobre a impossibilidade destas práticas em uma sociedade moderna, com o tamanho da população que tem os estados hoje. 0 argumento de Dahl sobre o número de cidadãos que pode ser envolvido em um debate é um exemplo disto (DAHL, 1998). 
No entanto, talvez seja esta a maior tarefa da Ciência Política. Em um país em que há um baixo nível de confiança nas instituições e menor ainda no comportamento dos representantes políticos, contribuir na construção de soluções para uma sociedade mais justa e equilibrada é o desafio. O aprimoramento das experiências aqui descritas e analisadas pode contribuir neste objetivo.

Rodrigo Stumpf González é Doutor em Ciência Política pela Universidade Federal do Rio Grande do Sul. Professor do Programa de Pós-Graduação em Ciência Política da UFRGS.

E-mail: rsg65@terra.com.br

\section{Referências}

BAQUERO, Marcello. A vulnerabilidade dos partidos políticos e a crise da democracia na América Latina. Porto Alegre: UFRGS, 2000.

BOBBIO, Norberto. O futuro da democracia - uma defesa das regras do Jogo. Rio de Janeiro: Paz e Terra, 1986.

BOSCHI, Renato Raul. Movimentos coletivos no Brasil urbano. Rio de Janeiro: Zahar, 1983.

(Org.). A arte da associação - política de base e democracia no Brasil. Rio de Janeiro: IUPERJ/Vértice, 1987.

CARONE, Edgar. A República liberal: Evolução política (1945-1964). São Paulo: Difel, 1985.

DAHL, Robert. On Democracy. New Haven: Yale University Press, 1998.

DINIZ, Eli. O Estado Novo: estrutura de poder e relações de classes. In: FAUSTO, Boris (Org.). História geral da civilização brasileira. São Paulo: DIFEL, 1981. Tomo II (O Brasil republicano). v. 3 (Sociedade e Política 1930-1964). p. 77-120.

FEDOZZI, Luciano. Orçamento Participativo. Reflexões sobre a Experiência de Porto Alegre. Porto Alegre: Tomo Editorial, 1997.

GONZÁLEZ, Rodrigo Stumpf. Política municipal, participação popular e legitimação: o papel político do orçamento participativo em Porto Alegre. In: Anais do VII Encontro Nacional da ANPUR. Recife, 7., 1997. 
. Participação popular, cultura política e ação coletiva: uma análise do orçamento participativo em Porto Alegre. In: GONZALEZ, Rodrigo; BAQUERO, Marcello; CASTRO, Henrique de. A construção da democracia na América Latina - estabilidade democrática, processo eleitorais, cidadania e cultura política. Porto Alegre: Ed. UFRGS, 1998. p. 190-214.

- Democracia e conselhos de controle de políticas públicas - uma análise comparativa. 2000. 340 f. Tese (Doutorado em Ciência Política) Programa de Pós-Graduação em Ciência Política, UFRGS, Porto Alegre, 2000.

- Capital social, ação coletiva e orçamento participativo. In: Baquero, Marcello (Org.) Reinventando a sociedade na América Latina - cultura política, gênero, exclusão e capital social. Porto Alegre: Ed. UFRGS, 2001. p. 150-172.

- Novos espaços da democracia no Brasil: a participação popular na definição do orçamento público. In: GONZÁLEZ, Rodrigo S.(Org.) Perspectivas sobre Participação e democracia no Brasil. Ijuí: Editora Unijuí, 2007. p. 145168.

- Democracia, cultura política e experiências participativas na América Latina. In: BAQUERO Marcello (Org). Cultura(s) Política(s) e democracia no século XXI na América Latina. Porto Alegre: Ed. UFRGS, 2011. p. 47-68.

GONZÁLEZ, Rodrigo Stumpf; DINIZ, Fernando Montardo. Instrumentos legais para a prática da cidadania no Brasil: voto, plebiscito, referendo e iniciativa popular. Estudos Jurídicos, São Leopoldo, v. 35, n. 94, p. 51-72, mai-ago. 2002.

JACOBI, Pedro. Movimentos populares urbanos e resposta do Estado: autonomia e controle versus cooptação e clientelismo. In: BOSCHI, Renato Raul (Org.). Movimentos coletivos no Brasil urbano. Rio de Janeiro: Zahar, 1983. p. $145-179$.

. Movimentos sociais e políticas públicas. São Paulo: Cortez, 1989.

LEAL, Victor Nunes. Coronelismo, Enxada e Voto. São Paulo: Alfa-Ômega, 1986.

MORONI, José Antônio. Participamos, e daí?. Observatório da cidadania. Texto para debate. Ibase, Rio de Janeiro, nov. 2005. Disponível em: <http://www.ibase.br/pubibase/media/Participacao_Moroni.pdf> Acesso em: 29 nov. 2011. 
O direito à participação no governo Lula. In: Conference on Social Welfare. Brasília, 32., 2006. Disponível em: <http://www.icsw.org/globalconferences/Brazil2006/papers/jose_antonio_moroni.pdf>. Acesso em: 05 dez. 2011.

RAICHELIS, Raquel. Esfera pública e conselhos de assistência social caminhos da construção democrática. São Paulo: Cortez, 1998.

RIO GRANDE DO SUL. Assembléia Legislativa. Fórum Democrático de Desenvolvimento Regional - O Rio Grande debate o seu futuro - Seminário Estadual. Porto Alegre: ALERGS, 1999.

SADER, Eder. Quando novos personagens entraram em cena. Rio de Janeiro: Paz e Terra, 1988.

SANTOS, Boaventura de Souza. Democratizar a democracia: os caminhos da democracia participativa. Rio de Janeiro: Civilização Brasileira, 2002.

SCHERER-WARREN, IIse; KRISCHKE, Paulo J. Uma revolução no cotidiano? Os novos movimentos sociais na América do Sul. São Paulo: Brasiliense, 1987.

SINGER, Paul. Movimentos de bairro. In: SINGER, Paul; BRANT, Vinicius Caldeira (orgs.). São Paulo: o povo em movimento. Petrópolis: Vozes, 1980. p. 83-108.

WHITAKER, Francisco et. al. Cidadão constituinte. A saga das emendas populares. Rio de Janeiro: Paz e Terra, 1989.

WOLFE, Alan. O mal-estar do capitalismo: democracia, socialismo e as contradições do capitalismo avançado. In: CHAUÍ, Marilena et. al. A questão da Democracia. Rio de Janeiro/São Paulo: Paz e Terra/CEDEC, 1980. p. 1352.

Texto recebido em 29/02/2012.

Aprovado em 12/04/2012. 